\title{
CEREBRAL PALSY IN GIYANI
}

- Joanne Potterton BSc Physiotherapist Physiotherapy Department, University of the Witwatersrand

\section{INTRODUCTION}

Giyani is situated approximately $180 \mathrm{~km}$ from the Zimbabwe/South Africa border. The area has suffered under a severe drought during the past seven years and temperatures reach $42^{\circ} \mathrm{C}$ during the summer. Giyani was the capital of the former "Bantu Homeland" Gazankulu.

\section{ABSTRACT}

This study sets out to establish the epidemiology of cerebral palsy in the drought stricken Giyani district in the Northern Province. Seventynine children with cerebral palsy were assessed at Nkhensani hospital. The cause and type of cerebral palsy were established as well as the main concerns of the parents. Thirty-two percent of cerebral palsy was found to be due to postnatal causes, which may be attributed to the prevalence of meningitis and gastroenteritis. Only sixteen percent of the children had diplegia, which is in keeping with findings in other third world countries. Major concerns expressed by the parents included issues of education and institutionalisation as facilities for children with disabilities in this area are inadequate. An obvious need exists to impart neuro-developmental skills to therapy assistants and to parents who play the biggest role in managing children with cerebral palsy in the Northern Province.
Accommodation in the area varies from western type houses, found in towns and which have water and electricity, to traditional mud huts with thatched roofs which usually have no electricity. In the villages water is collected from rivers or from communal water points. At the time this study was being conducted large number of Mozambican refugees (15 000) stayed in makeshift shacks in a refugee camp $2 \mathrm{~km}$ outside Giyani. They were part of a voluntary repatriation programme run by the United Nations. However, this was a slow process and during this time the refugees made use of the health services in Giyani.

Employment opportunities in this areas are limited and many men become migrant workers, going to the cities to work on the mines or in industry. They often return home only at Christmas time. This means that most households are headed by women who supplement the money sent home by their husbands by subsistence farming. Maize and pumpkins are most commonly grown. Unemployment and poverty are major problems in Giyani. The Northern province is the poorest area in the country, the average gross geographic annual per capita product was only R1266 in $1993^{1}$.

Health services in the Giyani district are inadequate. Nkhensani hospital is a secondary hospital with 300 beds. It has no intensive care or high care facilities and only minor surgical procedures are carried out. It has 12 satellite primary health care clinics which vary in distance from $2 \mathrm{~km}$ to $57 \mathrm{~km}$ from the hospital. Transport between the clinics and the hospital is unreliable and patients often have to walk. The tertiary hospital to which patients requiring intensive care or major surgery are sent, is $300 \mathrm{~km}$ away in Garankuwa and again transport is unreliable. Nkhensani hospital is understaffed and poorly equipped, eleven medical officers service the hospital and all the clinics. The hospital has no regis- 
trars or consultants. Most of the clinics lack even the most basic facilities, including electricity and running water, and are run by nurses and nursing assistants. The hospital does not have enough doctors to staff the clinics on a permanent basis.

Malnutrition is common especially amongst children. Diarrhoeal disease being the major cause of death in children between $1-5$ years of age ${ }^{2}$.

All children in the sample attended the Cerebral Palsy clinic at Nkhensani hospital. The clinic was started in January 1994, as no formal rehabilitation services existed in the area for children with cerebral palsy. The children all came from the Giyani district and relied on public transport or walked to the clinic.

\section{METHOD}

A study was undertaken to establish the epidemiology of cerebral palsy in the area as well as to find out what the main concerns and problems facing parents and caregivers were.

Seventy-nine children attended the clinic on a regular basis during 1994. All the children where assessed by the same physiotherapist. A nursing assistant assisted as a translator as many people in the area do not speak or understand any English.

A thorough history was taken from the caregiver accompanying the child. This included pregnancy and birth history, developmental progress, and any medical or surgical problems. All children born in South African hospitals or clinics are given a "Road to Health Card" on which their birth details are recorded. This chart is supposed to be presented at every clinic or hospital visit and all immunisations, height, weight and hospital admissions are documented on it.

All caregivers and mothers interviewed were asked to express their main concerns and problems in their day to day management of the child.

The causes of CP included in this study were defined as follows: "Unknown" when the caregiver could not recall any incident in the child's history which may have given rise to the problems. Due to the problems experienced with obtaining an accurate history and the fact that only $21 \%$ of women have regular antenatal checks ${ }^{1}$ it was not possible to differentiate between prenatal and perinatal causes.

"Perinatal" causes therefore include history of bleeding during pregnancy, long labour (more than twelve hours), difficult birth or if the baby took a long time to cry or needed to be resuscitated. "Postnatal" causes include neonatal seizures, infection, kernicterus and trauma. Each child was assessed thoroughly by the same therapist using neuro-developmental assessment principles as taught on Bobath courses.

\section{RESULTS}

At their first physiotherapy assessment the ages of the children varied from one day to fifteen years old.

\begin{tabular}{|l|c|}
\hline \multicolumn{2}{|c|}{ Table I: Types of cerebral palsy } \\
\hline Spastic & \\
\hline Qudriplegic & $29 \%$ \\
\hline Diplegic & $16 \%$ \\
\hline Hemiplegic & $19 \%$ \\
\hline Athetoid & $2.5 \%$ \\
\hline Mixed & $1 \%$ \\
\hline Hypotonic & $15 \%$ \\
\hline \hline
\end{tabular}

It was found that in $32 \%$ of cases, cerebral palsy was due to postnatal causes, while $46 \%$ of cases were due to perinatal causes. The cause of the remaining $22 \%$ of cases was unknown. The contribution of post-natal causes is very high compared to Sweden where postnatal causes account for $3 \%$ of cerebral palsy cases only ${ }^{3}$.
When looking at the types of $\mathrm{CP}$ found, it is interesting to note that these correlate well to the types of $\mathrm{CP}$ found in the Ciskei and in Nigeria ${ }^{3}$. In these developing countries the number of cerebral palsy children with diplegia is relatively low (see table 1). Twentynine percent of children attending the cerebral palsy clinic in Giyani had spastic quadriplegia, this was commonly associated with a history of birth asphyxia and is cause for some concern. Sixty-three percent of the children attending the CP clinic at Nkhensani hospital were males and $28 \%$ of the children seen were on medication for epilepsy.

\section{DISCUSSION}

Problems were frequently encountered during the assessment of children as the caregiver was often not the mother of the child and was unable to give accurate details. Birth and medical histories were often poorly recorded in the child's hospital file. In rural areas in South Africa a large proportion (30\%) of babies are still delivered at home, without a midwife or doctor being present ${ }^{1}$. In such cases unless the mother herself brought the child to the clinic it was extremely difficult to obtain an accurate birth history.

Unfortunately only $54 \%$ of caregivers in rural areas have a Road to Health Card ${ }^{1}$. If the child was born at home the parents may never have received a card or they may have lost it or simply have forgotten to bring it with them. This card is therefore not a reliable source of information.

The fact that such a high percentage ( $32 \%$ ) of the cerebral palsy seen was due to postnatal causes could be due to the high incidence of meningitis and gastroenteritis in rural South Africa. Both these diseases can lead to permanent brain damage if they are not diagnosed and treated early.

The low numbers of diplegia children found correlates well with findings in other third world settings ${ }^{3}$. This is probably due to the fact that premature babies are less likely to survive in areas where there are no neonatal intensive care units. (Intraventricular haemorrhages are a common cause of diplegia.)

The most common and most pressing problem experienced by more than eighty percent of mothers and caregivers was one of lack of daycare or institutionalisation. Many women were unable to go to work because of the constant demands placed on them in caring for a disabled child. Many felt that, if they had somewhere to leave the child during the day (or for longer), they would be able to get a job and thus improve the economic status and well-being of the whole family. Unfortunately no day care centres for disabled children exist in the Giyani area and most creches are reluctant to accept children with special needs. There is one institution in Giyani (Evuxakeni) which provides full time care and accommodation for mentally and physically disabled adults and children. This centre was not viewed as acceptable by most parents and had a very poor reputation in the community.

Parents also expressed concern about their children's education. There is one school $140 \mathrm{~km}$ from Giyani which caters for children with physical disabilities only. It does not accept children with below normal IQs and has a long waiting list. It has a weekly boarding facility but even so was too far for most people to consider. Main streaming is not a solution for most children in this area at present, as classes a re overcrowded and many primary school teachers do not have any formal training. Normal schools are not accessible to children with physical disabilities and the staff have no training in coping with children with special needs. There is only one remedial teacher in Giyani who serves all the primary and high schools.

Caregivers and mothers were concerned about the future of their children and worried about who would take over their care once they themselves were too old. Many expressed regret that the traditional extended family system was breaking down as they felt that this would have provided more support.

A problem which was mentioned in ten percent of cases was lack of acceptance of the child by the family and community. Some 
people still hold the belief that if a child is born disabled it means that his mother did something "evil" during her pregnancy. Children who have fits or abnormal movements (eg athetosis) are sometimes thought to be possessed by an evil spirit. These beliefs are often deep seated and it is very difficult to challenge them without offending people.

As a physiotherapist I found it both challenging and frustrating to be working in a culture so different from my own. The fact that I was not fluent in Shangaan and had to rely on an interpreter proved a big problem as it made meaningful conversation with parents difficult.

Many mothers and caregivers reported difficulties with getting to the hospital to obtain repeats of their anticonvulsants and so compliance was generally poor and in most cases fitting was not well controlled.

The long distances which people had to travel combined with expensive, unreliable transport made regular follow up visits very difficult to achieve. It was always valuable to go on home visits, this was however a very time consuming process and only two or three children could be seen in a day due to the vast distances which had to be covered.

The lack of support from professional staff also made working difficult. There was no speech therapist to consult about feeding and speech difficulties and the occupational therapist working at the hospital expressed little interest in getting involved in any sort of team work. This meant that the physiotherapist had a large work load and struggled to spend enough time with each child. There was no paediatrician or neurologist at the hospital, which resulted in the physiotherapist often trying to cope with problems of which she had little knowledge, which proved to be both frustrating and demoralising.

Another problem was the fact that there were very few options for referring a child to a creche or schnol. Many of the children showed potential for some form of education but due to lack of facilities this could never be realised. This was heartbreaking for parents and children alike, many of whom were desperate to go to school like the other children in their village. As mentioned previously mainstreaming was not an option except for the children who were very mildly affected.

Most mothers and caregivers with children with spastic quadriplegia experienced problems with feeding their children. Not only did many of the children have difficulty chewing and swallowing, but many women where also concerned about the quality and quantity of food they were able to provide for the child. Protein malnutrition is still a huge problem throughout South Africa ${ }^{2}$ and this was definitely evident in many of these children.

Explaining the child's condition and prognosis to the mother or caregiver was not always easy. The western biomedical model on

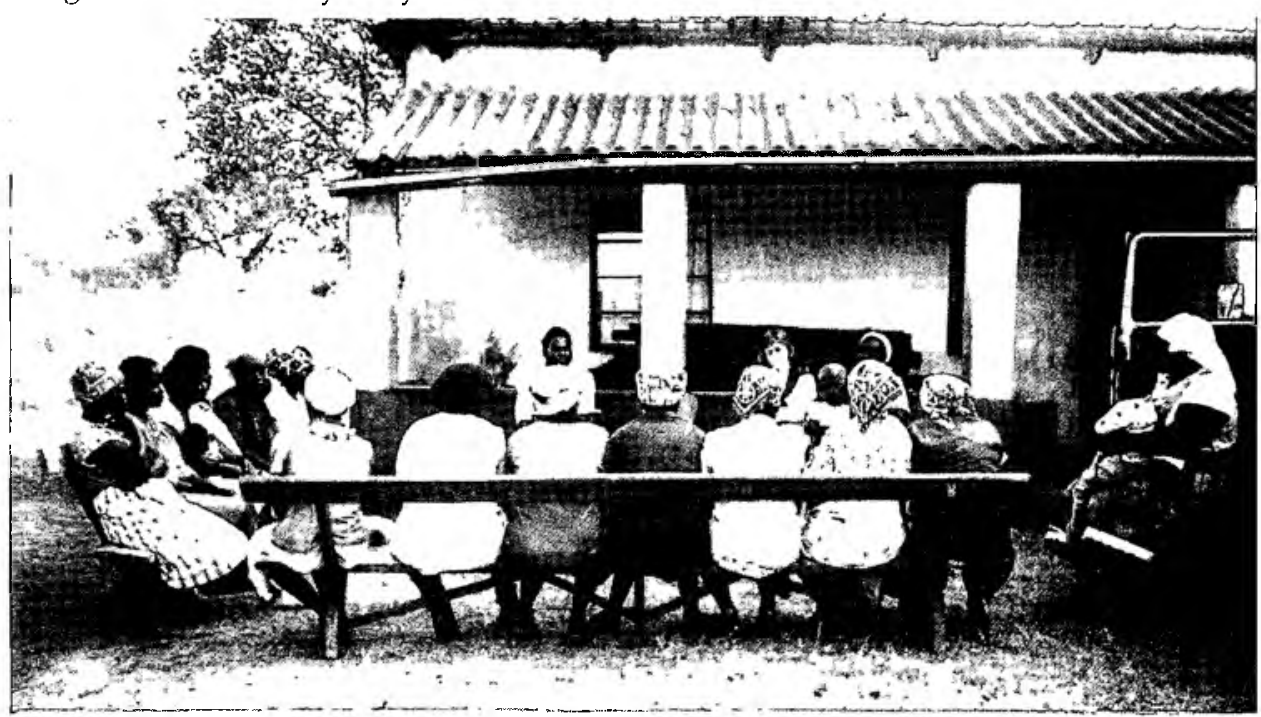

which so much of physiotherapy theory is based was a totally foreign concept to the majority of parents, many of whom had little or no formal education. Cognisance has to be taken of cultural issues and people's world views have to be considered before one can even attempt to discuss the pathogenesis of cerebral palsy.

It is also important to have a thorough understanding of cultural norms and practices before giving a home programme. Traditional ways of handling and feeding babies are deeply ingrained and it cannot be expected that people should change the way they do things simply because the physiotherapist asks them to. An example of this is the way in which small babies are often fed. The baby is placed lying on its back between the mothers legs, its mouth is then filled with porridge and if it does not swallow immediately the mother blocks its nose until it does. Obviously this method of feeding can easily lead to aspiration especially in a child with incoordinated swallowing. It is however, the way Shangaan babies have been fed for centuries and few mothers are going to take kindly to being told by someone from a different culture that it is unacceptable.

\section{CONCLUSION}

Cerebral Palsy is a huge problem in the Northern Province as I am sure it is in other rural areas in South Africa. As physiotherapists we have to decide where our priorities lie and what we are going to do as a profession in order to make our services more accessible to those who really need them.

It is obvious that rural hospitals in South Africa are understaffed with rehabilitation personnel and every attempt has to be made to attract competent, committed professionals to work in these areas. This is obviously a long term goal and certain steps must be taken in the meantime.

* Therapy assistants and community based rehabilitation workers must be given sufficient knowledge and skills to manage children with cerebral palsy. Basic NDT skills must be transferred to the people who need them most.

* Mothers of children with cerebral palsy should be empowered to demand their children's rights to a healthy lifestyle and education.

* Awareness of the rights of disabled children must be stressed in rural communities.

* Doctors and nurses in rural areas must be made aware of the importance of early screening and referral of children with developmental problems.

* People must lobby local and national government for more and better facilities for disabled children.

Hopefully with the government's commitment to improving primary health care, and especially the health of women and children ${ }^{4}$, we will start to see maternal and child health improving in South Africa and the incidence of cerebral palsy beginning to drop.

\section{REFERENCES}

1. A national household survey of health inequalities in South Africa: Prepared by community agency for social enquiry for the Henry J Kaiser Family Foundation, Oct 1995

2. Harrison D. The Rural Child: A War Against Death and Discase. Mathlasedi Nov/Dec 1991.

3. Saloojee $\mathrm{H}$. The Epidemiology of CP; Presentation at NDT Course. Soweto, Feb 1995.

4. African National Congress. A National Health Plan for South Africa May 1994. Johannesburg, South Africa. 